\title{
Exploring Factors Leading to Quality Online Learning in the Era of Covid-19: A Correlation Model Study
}

\author{
Ghulam Safdar $^{1, *}$, Abdur Rauf ${ }^{2}$, Rahman Ullah ${ }^{3}$, Atif Ur Rehman ${ }^{4}$ \\ ${ }^{1}$ Department of Arts \& Media, Foundation University Islamabad, Pakistan \\ ${ }^{2}$ Department of Communication \& Media Studies, Khushal Khan Khattak University Karak Khyber Pakhtunkhwa, Pakistan \\ ${ }^{3}$ Department of Journalism \& Mass Communication, Kohat University of Science \& Technology Kohat, Pakistan \\ ${ }^{4}$ School of Media \& Design Shanghai Jiao Tong University, China
}

Received August 9, 2020; Revised November 9, 2020; Accepted November 19, 2020

\section{Cite This Paper in the following Citation Styles}

(a): [1] Ghulam Safdar, Abdur Rauf, Rahman Ullah, Atif Ur Rehman, "Exploring Factors Leading to Quality Online Learning in the Era of Covid-19: A Correlation Model Study," Universal Journal of Educational Research, Vol. 8, No. 12A, pp. 7324 - 7329, 2020. DOI: 10.13189/ujer.2020.082515.

(b): Ghulam Safdar, Abdur Rauf, Rahman Ullah, Atif Ur Rehman (2020). Exploring Factors Leading to Quality Online Learning in the Era of Covid-19: A Correlation Model Study. Universal Journal of Educational Research, 8(12A), 7324 7329. DOI: 10.13189/ujer.2020.082515.

Copyright $@ 2020$ by authors, all rights reserved. Authors agree that this article remains permanently open access under the terms of the Creative Commons Attribution License 4.0 International License

\begin{abstract}
The spark of Covid-19 spread in the world in the start of 2020. When it destroyed other segments of social life, it also impacted education negatively. The closure of educational institutes raised question mark on stakeholders in this age of technological advancement. When other counties of the world adopted alternative ways of education, Pakistan also adopted the policy of online education using available technological resources. The objective of the study was to explore the students' experience of online learning and satisfaction level among them. Using survey method to get the views of students studying in Foundation University of Islamabad, researchers designed well structure simple and easy to understand questionnaire. The questionnaire consisted of 23 close-ended questions and was distributed via email and Whatsapp groups designed by departments of the university. In the period of two weeks, $n=273$ students responded to the questionnaire. The findings of the study revealed that in online learning comfortability with computer usage, self-motivation, confidence and time spending on computer significant correlate to quality education and lead to better educational understanding while getting online education. The study concluded that students found satisfied with online learning. Familiarity with technological tools found positive aspect for students to get online education easily.
\end{abstract}

Keywords Online Learning, Quality Education,
University Students, Covid-19

\section{Introduction}

Covid-19 pandemic has not only affected business and daily life of people but also the education system in the world. The rapid spread of disease has led to the closure of educational institutions. To deal with such crisis, universities are required to adopt advanced technology to enable effective online learning (Safdar \& Khan, 2020). Development of online learning infrastructure created alternative learning environment for the students and to avoid disrupted education system (Kumar, 2019). Almost all the institutions have established online systems so that course contents could be deliver online and may engage students and conduct assessments in better way (Goshtasbpour et al., 2020; Safdar et al., 2018).

Covid-19 outbreak while being a hazard to humanity (Safdar, 2020). It has evolved educational institutes to endow in online learning system. Online learning system is an alternative solution to teach students to use web-based software for managing courses, distributing tasks and tracking record of students over the internet (Keis et al., 2017; Khan et al., 2018). Implementation of advance information communication technology has evolved alternative way to conduct classes that enables direct 
two-way communication among students and teachers to deliver and to get learning content among the students (Tanji \& Vasantha, 2016; Jansen et al., 2016; Shabir et al., 2015).

Various online software have features such as whiteboards, quizzes, polls, chat rooms, surveys and discussion forums that able the teachers to teach online along with course content (Shabir et al., 2014a). Online web-based software offers convenient and productive ways to achieve learning goals (Safdar et al., 2020). Microsoft Teams, Google meet, Moodle and Edmodo online based software with video applications are being used for learning management system in Pakistan (Barbera \& Clara, 2012). Zoom, Skype, WebEx and Adobe connect are also being used for video conferencing (Shabir et al., 2014b).

According to Pakistani literature about online learning recently a few studies found supporting online learning in Pakistan including four medical universities of Punjab and Kyber Pakhtunkhwa studies on online learning in this era of Covid-19 (Jawaid \& Ashraf, 2012; Iqbal et al., 2016; Sethi et al., 2019). These studies discussed about compensation, confines and recommendations for online learning during Covid-19 pandemic era (Mukhtar et al., 2020). Conducted studies reported good technology access, online learning and attentiveness for online debate among students.

In advancement in technologies and increase the use of online modalities during Covid-19 outbreak, it is essential to review their efficiency with regards to learning and teaching from various institutions (Schwartz et al., 2020). Hence, current research study explores the students' experience of online learning in Pakistan during covid-19 outbreak. Recently Higher Education Commission (HEC) of Pakistan is in the progression of implementing online learning across all the universities of Pakistan to continue process of teaching and learning without any hurdle. Finding of the study will help to identify and tackle issues faced by students while learning online.

\section{Present Study}

The present study deals with experiencing online learning in this age of Covid-19 that how online learning is an alternative way to get education being stayed home stayed safe. The concept of online learning is not new but in developing countries like Pakistan, it is challenging task to conduct online education not only for government and educational institutes but also for students. Keeping in the mind the concept of online learning among students, researchers designed nine hypotheses that, online learning cause computer usage comfort-ability among students (H1); Online learning increase confidence among students (H2); Online learning cause self-motivation among students (H3); Online learning create interest to spend more time on computers (H4); Online learning can cause quality education (H5); Computer usage comfort-ability cause quality education (H6); Confidence cause quality education (H7); Self-motivation cause quality education (H8); and more time spending on computer cause quality education (H9) to measure the phenomenon of concern.

\section{Method}

\section{Population}

Study was survey based and data was collected from Foundation University (A Federal Chartered University) located in capital city of Islamabad, Pakistan having three campuses with nine (9) faculties. Students' statistics of the university has more than 7000 students including male and female. Foundation University consists of a variety of faculties including medical, engineering \& IT, business \& economics and social sciences. Hence the representation and responses of students from all the faculties with different areas of specialization made able the researchers to conclude results on broader scenario.

\section{Procedure}

\section{Sample \& Technique}

Current research study was conducted using survey method and well-structured online questionnaire was designed including 23 items. Questionnaire consisted of close-ended questions and each question consisted of five elements Likert scale where $1=$ strongly agree and 5=strongly disagree was reported. Questionnaire was designed in simple and easy language to avoid any ambiguity. Data were collected from $n=273$ students studying in Foundation University Islamabad, Pakistan. Questionnaire was designed online using Google forms and using purposive sampling technique, the link of questionnaire was sent to students via emails and WhatsApp groups who are taking online classes from home due to Covid-19 outbreak. Targeted public was under graduate, graduate and post graduate students of three campuses of Foundation University located its main campus at Islamabad and sub campuses in Rawalpindi and Sialkot. Among nine (9) faculties four are in main campus, three are in Rawalpindi Campus and two are in Sialkot campus. In one week, duration $n=273$ respondents submitted their responses.

\section{Measures}

A detailed and easy measure to understand questionnaire was designed to get the response from targeted public. Researchers conducted pilot study of thirty respondents to check the reliability of questionnaire and high reliability $(\alpha=87)$. The develops for all factors had a Cronbach's alpha coefficient of more than 0.8 . Face validity and content validity were additionally checked before information assortment and dependability testing to guarantee the validity of the instrument. After data 
collection, data was processed using SPSS 20 and statistical tests were applied.

Student comfort-ability with computer usage: Respondents were asked to answer whether they feel comfortable in computer usage ( $1=$ Strongly Agree, 2=Agree, 3=Neutral, 4=Disagree, 5=Strongly Disagree). Results showed that five items were loaded in single factor and were average created scale $(\mathrm{M}=2.33, \mathrm{SD}=1.173)$.

Confidence while online presentation: Respondents were asked to answer whether they feel confident while giving presentation online as compared to face to face class. Results showed that five items were loaded in single factor (1=Strongly Agree, 2=Agree, 3=Neutral, 4=Disagree, $5=$ Strongly Disagree) and were average created scale $(\mathrm{M}=2.38, \mathrm{SD}=1.189)$.

Self-motivation role in online learning: Respondents were asked to answer whether they feel that self-motivation plays an important role in online learning. Results showed that five items were loaded in single factor (1=Strongly Agree, 2=Agree, 3=Neutral, 4=Disagree, 5=Strongly Disagree) and were average created scale $(M=2.14$, $\mathrm{SD}=1.347)$.

Time spend on computers usage and online learning: Respondents were asked to answer whether they feel that more spending time in using computer helps more in online learning. Results showed that five items were loaded in single factor (1=Strongly Agree, 2=Agree, 3=Neutral, 4=Disagree, $5=$ Strongly Disagree) and were average created scale ( $\mathrm{M}=2.23, \mathrm{SD}=1.424)$.

High quality learning without face-to-face interaction: Respondents were asked to answer whether they feel that high quality learning can take place online without face-to-face interaction. Results showed that five items were loaded in single factor $(1=$ Strongly Agree, $2=$ Agree, $3=$ Neutral, 4=Disagree, 5=Strongly Disagree) and were average created scale $(\mathrm{M}=2.31, \mathrm{SD}=1.462)$.

Control Variables: Faculty, Gender, Class were control variables. Respondents were asked to respond to their Faculty ( $1=$ Foundation University Medical College, 2=College of Dentistry \& Hospital, 3=Institute of Rehabilitation Sciences, 4=College of Nursing, 5=Faculty of Engineering \& IT, 6=Faculty of Arts \& Social Sciences, 7=Faculty of Management Sciences, 8=Faculty of Engineering \& IT Sialkot Campus, 9=Faculty of Management Sciences Sialkot Campus). In addition, gender (1=Male, $2=$ =Female) and class variable (1=Undergraduate, $2=$ Graduate, $3=$ Post Graduate).

\section{Data Collection}

Below table shows the demographics of respondents. Demographics of respondents include faculty to whom respondents belongs as data were collected from nine faculties of Foundation University. Respondent's gender male or female and class of respondent in which he/she is enrolled i.e. under-graduate to post-graduate.

Table 1. Demographics of Respondents

\begin{tabular}{|c|c|c|c|c|}
\hline $\begin{array}{l}\text { Sr. } \\
\text { No. }\end{array}$ & $\begin{array}{c}\text { Demographic } \\
\text { Characteristics }\end{array}$ & Description of Characteristics & $\mathbf{F}$ & $\%$ \\
\hline \multirow{10}{*}{1} & \multirow{10}{*}{ Faculty } & Foundation University Medical College & 29 & 10.62 \\
\hline & & College of Dentistry \& Hospital & 24 & 8.79 \\
\hline & & Institute of Rehabilitation Sciences & 22 & 8.05 \\
\hline & & College of Nursing & 19 & 6.95 \\
\hline & & Faculty of Engineering \& IT & 37 & 13.55 \\
\hline & & Faculty of Arts \& Social Sciences & 51 & 18.68 \\
\hline & & Faculty of Management Sciences & 41 & 15.01 \\
\hline & & Faculty of Engineering \& IT Sialkot Campus & 22 & 8.05 \\
\hline & & Faculty of Management Sciences Sialkot Campus & 88 & 32.23 \\
\hline & & Total & 273 & 100.00 \\
\hline \multirow{3}{*}{3} & \multirow{3}{*}{ Gender } & Male & 153 & 56.05 \\
\hline & & Female & 120 & 43.95 \\
\hline & & Total & 273 & 100.00 \\
\hline \multirow{4}{*}{4} & \multirow{4}{*}{ Class } & Under Graduate & 207 & 75.82 \\
\hline & & Graduate & 51 & 18.68 \\
\hline & & Post Graduate & 15 & 5.49 \\
\hline & & Total & 273 & 100.00 \\
\hline
\end{tabular}


Table 2. Correlation, Mean, Standard Deviation

\begin{tabular}{|c|c|c|c|c|c|c|c|c|}
\hline & 1 & 2 & 3 & 4 & 5 & 6 & M & SD \\
\hline Online Learning & 1 & & & & & & 1.19 & .393 \\
\hline Computer usage comfort-ability & $.251^{* *}$ & 1 & & & & & 1.01 & .120 \\
\hline Confidence & $.604^{* *}$ & $.152^{*}$ & 1 & & & & 1.39 & .489 \\
\hline Self-motivation & $.829^{* *}$ & $.303^{* *}$ & $.501^{* *}$ & 1 & & & 1.14 & .347 \\
\hline Time spend on computer & $.877^{* *}$ & $.220^{* * *}$ & $.689^{* *}$ & $.727^{* *}$ & 1 & & 1.23 & .424 \\
\hline High quality Education & $.728^{* *}$ & $.183^{* *}$ & $.830^{* *}$ & $.603^{* *}$ & $.830^{* *}$ & 1 & 1.31 & .462 \\
\hline
\end{tabular}

$*<0.05$ (2-tailed), $* *<0.01$ (2-tailed)

\section{Results}

Table 2 shows correlation, mean and standard deviation of assumed hypotheses. The first hypothesis online learning cause computer usage comfort-ability correlation value $.251^{* *}$ shows positive correlation between online learning and computer usage comfort-ability at 0.01 level hence the H1 supported. The second hypothesis online cause confidence among students' correlation value .604** shows positive correlation among variables at 0.01 level so H2 supported. The third hypothesis online learning and self-motivation correlation value $.829 * *$ shows positive correlation among variables at 0.01 level hence H3 supported. The fourth hypothesis online learning because time spending on computer correlation value $.877^{* *}$ shows positive correlation among variables at 0.01 level, hence $\mathrm{H} 4$ supported. The fifth hypothesis online learning leads to quality education, the correlation value $.728^{* *}$ shows significant positive correlation among variables at 0.01 level hence H5 supported. The sixth hypothesis computer usage comfort-ability leads to quality online education, the correlation value $.183^{* *}$ shows positive correlation among variables at 0.01 level so H6 supported. The seventh hypothesis confidence cause quality education, the correlation value $.930^{* *}$ shows positive correlation among variables at 0.01 level so $\mathrm{H} 7$ supported. The eighth hypothesis self-motivation leads to quality online education, the correlation value $.603^{* *}$ shows positive correlation among variables at 0.01 level hence H8 supported and the ninth hypothesis the habit of spending long times on computer leads to quality online learning, the correlation value $.830^{* *}$ shows positive correlation among variables at 0.01 level hence H9 also supported. Students believed that online learning with audio, video and textual content enhanced their learning capabilities. When students found satisfactory with online learning system, it also found some complaints like internet connectivity, low speed of internet, lack of equal opportunity due to different geographical regions.

\section{Discussion}

Current research study explores online learning experience of students in Foundation University Islamabad in Covid-19 situation. Study interprets students' view point about their expertise of learning online using digital tools i.e. computers, cell phones etc. Almost all the students $98.5 \%$ argued that they were comfortable using computers and able to get access easily on regular basis. As Safdar \& Khan (2020) stated that to deal with such crisis universities requires adopting advance technology to enable effective online learning. Availability of internet also found common among students and the use of keyboard among students found easy and familiar. As Kumar (2019) argued that development of online learning infrastructure created alternative learning environment for the students and avoided disrupted education system. Reading, typing, listening and speaking skills online were enjoyable and easy for students during class. Response regarding online quiz and presentation also were satisfactory among students while giving three hours in a week to a course found unsatisfactory. Self-motivation and work independently were appreciative and downloading course content and software and installation also found positive among students. Timely submitting assignments online, practice of working many hours on computers, familiarity with email and web-based applications were also satisfactory among university students. On the other hand, students were found complaining that they missed their fellows and students and the days of face to face classes with the hope that those days will return soon. They agreed with the idea of online learning in this covid-19 outbreak situation. As Goshtasbpour et al., (2020) and Safdar et al., (2018) concluded in their research that almost all the institutions tried to establish best online system and explore how course content can be delivered online, engage students and conduct assessments in better way. The overall finding of the research revealed that the understanding level online lectures found better in students and they argued that they feel comfortable in asking the tutor questions during online class like asking in face to face communication in real class. Furthermore, overall findings of the study show that quality education can take place online without face to face communication.

\section{Conclusions}

The study interpreted perspectives of online learning among university students in the age of Covid-19. It is 
concluded that online education is supple, alternative and efficient cause of teaching and learning among educational institutions along with a few pitfalls. Most of the students agreed that online learning is a better option of distance learning with easy management and convenience with less use of resources and time. Students found familiar with technological tools like computer related devices to access educational content online. Understanding level also found satisfactory and involvement of students in presentation and asking question in case of any problem found also easy among students. Self-directed learning improves competency and encourages lifelong learning among university level students. Students believed that online learning with audio, video and textual content enhancing their learning capabilities. Where students found satisfactory with online learning system, it also found some complaints like internet connectivity, low speed of internet, lack of equal opportunity due to different geographical regions.

\section{Limitations of the Study}

Current research study was conducted only in one university situated in Capital area of Pakistan and reflected the students' opinions in one university. Students of nine faculties were selected as sample and data were collected from $n=273$ students that may not be sufficient. The results of only one university may not reflect students' opinions of all universities. In this way there may be a chance of biasness that results of one university may not be applied to all universities in the country. Additionally, researchers collected data by preparing self-constructed questionnaire, hence the chance of baseness may also be involved.

\section{REFERENCES}

[1] Akhtar K., Javed K, Arooj M., Sethi A. “Advantages, Limitations and Recommendations for online learning during COVID-19 pandemic era”. Pakistan Journal of Medical Sciences. Vol. 36, 2020. (No.Covid-19 S4). COVID19-S27-S31. doi: https://doi.org/10.12669/pjms.36. COVID19-S4.2785

[2] Barbera E, Clara M. "Time in e-Learning Research: A Qualitative Review of the Empirical Consideration of Time in Research into e-learning”. ISRN Educ. 2012. doi: $10.5402 / 2012 / 640802$

[3] Goshtasbpour F., Swinnerton B., Morris N.P. "Look who’s talking: Exploring instructors' contributions to Massive Open Online Courses”. British Journal of Educational Technology. Vol.51, no.1, pp. 228-244, 2020. doi:10.1111/bjet.12787

[4] Iqbal S, Shafiq A, Iqbal N. "Perceptions of undergraduate dental students towards e-Learning in Lahore Medical and
Dental College”. Pak J Med Heal Sci. vol.10, no.4, pp.1191-1193, 2016.

[5] Jansen R., Leeuwen A.V., Janssen J., Kester L., Kalz M. "Validation of the self-regulated online learning questionnaire”. Journal of Computing in Higher Education. Vol.29, pp. 6-27, 2016.

[6] Jawaid M, Ashraf J. "Initial experience of eLearning research module in undergraduate medical curriculum of Dow University of Health Sciences: Development and students perceptions”. Pak J Med Sci. vol.28, no.4, pp. 591-596, 2012.

[7] Keis O, Grab C, Schneider A, Ochsner W. "Online or face-to-face instruction? A qualitative study on the electrocardiogram course at the University of Ulm to examine why students choose a particular format”. BMC Med Educ. Vol.17, no.1, pp.194, 2017. doi: 10.1186/s12909-017-1053-6

[8] Khan A.W., Safdar G., Ashraf M. "Effects of Mobile Phone Usage on Social Behaviours of University Students: A Case study of Islamia University of Bahawalpur, Pakistan”. Global Media Journal Pakistan Edition. Vol.11, no.1, pp.1-26, 2018.

[9] Kumar S.C. "Awareness, benefits and challenges of e-learning among the students of Kurukshetra University Kurukshetra: A study”. Int J Inf Dissemination Tech. vol.8, no.4, pp.227-230, 2019. doi: 10.5958/2249-5576.2018.0004 8.1

[10] Safdar G. "Covid-19, Media Dependency and Fear of Death: Analysis of Pre, During and Post Infection among Affected People”. Psychiatria Danubina. In press. 2020.

[11] Safdar G. Khan A.W., Abbasi, A. "Role of Social Media for Promotion of Education in Southern Punjab”. Journal of Education Research. Vol.21, no.1, pp.73-85, 2018.

[12] Safdar G., Javed M.N., Amin S. "Use of Internet for Educational Learning among Female University Students of Punjab, Pakistan”. Universal Journal of Educational Research. Vol.8, no.8, pp.3371-3380, 2020. DOI 10.13189/ujer.2020.080809

[13] Safdar G., Khan A.W. "E-Learning: Current Scenario of Internet and Educational Learning among University Students of Punjab, Pakistan". Journal of Educational Research. Vol.23, no.1, pp.171-185, 2020.

[14] Schwartz AM, Wilson JM, Boden SD, Moore Jr TJ, Bradbury Jr TL, Fletcher ND. "Managing Resident Workforce and Education During the COVID-19 Pandemic: Evolving Strategies and Lessons Learned”. JBJS Open Access. Vol.5, no.2, pp.e0045, 2020. doi: 10.2106/JBJS.OA.20.00045

[15] Sethi A, Wajid A, Khan A. "E-Learning: Are we there yet?”. Prof Med J. vol.26, no.04, pp.632-638, 2019. doi: 10.29309/ TPMJ/2019.26.04.3367

[16] Shabir G., Hameed Y.M.Y., Safdar G., Gilani S.M.F.S "Impact of Social Media on Youth: A Case Study of Bahawalpur City". Asian Journal of Social Sciences and Humanities, vol.3, no.4, pp. 132-151, 2014a.

[17] Shabir G., Iqbal Y.W., Safdar G. "Demographics' Differences in Social Networking Sites Use: What 
Communication Motives Does it Gratify?” International Journal of Social Work and Human Service Practice, vol.2, no.5, pp.184-194, 2014b.

[18] Shabir G., Safdar G., Jamil T., Bano S. “Mass Media, Communication and Globalization with the perspective of $21^{\text {st }}$ century”. New Media and Mass Communication, vol.34 pp.11-15, 2015.

[19] Thanji M, Vasantha S. "ICT factors influencing consumer adoption of ecommerce offerings for education". Indian $\mathrm{J}$ Sci Tech. vol.9, no.32, pp.1-6, 2016. 